\title{
Teoria social da austeridade: para uma crítica do processo de precarização
}

\author{
Renato Miguel do Carmo \\ Instituto Universitário de Lisboa (ISCTE-IUL), Portugal \\ André Barata \\ Universidade da Beira Interior, Portugal
}

O objetivo central deste artigo é desenvolver uma interpretação e uma compreensão do fenómeno político-social da austeridade nas suas relações com a instauração de um regime social de existência precária que se abateu, a partir de 2008, sobre Portugal e alguns países da Europa. Deste propósito resultam outros dois objetivos parcelares: por um lado, pretendese caracterizar este processo como um regime social da precariedade nas suas condições existenciais mais estruturais, designadamente nas suas estruturas espaciotemporais; por outro, identificar os meios político-económicos pelos quais essas condições foram sendo instauradas, a partir de uma modificação profunda da vida social das populações. Analisar-se-ão as formas de desinstitucionalização decorrentes da implementação dos programas de austeridade e o seu impacto num conjunto de esferas sociais: na depreciação e desvalorização da atividade do trabalho, na incerteza da vivência espaciotemporal, no exercício da racionalidade no contexto da ação humana. Por fim, mostra-se como posicionamentos políticos de oposição à austeridade tendem a fundar a sua ação política subvertendo as condições espaciotemporais que a austeridade procura impor.

Palavras-chave: austeridade, ideologia política, teoria social, trabalho

\section{Teoría social de la austeridad: para una crítica del proceso de precarización}

El objetivo central de este artículo es desarrollar una interpretación y una comprensión del fenómeno político-social de la austeridad en sus relaciones con la instauración de un régimen social de existencia precaria, que se cernió a partir de 2008 sobre Portugal y algunos países de Europa. De este propósito resultan otros dos objetivos partícipes: por un lado, se pretende caracterizar este proceso como un régimen social de la precariedad en sus condiciones existenciales más estructurales, principalmente en sus estructuras espaciotemporales; por otro, identificar los medios político-económicos por los que esas condiciones

[Artigo submetido em 13 de abril de 2016. Aprovado em 30 de agosto de 2016.] 
han estado siendo aplicadas, a partir de una modificación profunda de la vida social de la ciudadanía. Serán analizadas asimismo las formas de desinstitucionalización producto de la implementación de los programas de austeridad y su impacto en un conjunto de ámbitos sociales: en la depreciación y minusvaloración de la actividad del trabajo, en la inseguridad de la vivencia espacio-temporal, en el ejercicio dela racionalidad en el contexto de la acción humana. Para concluir, se muestra como posicionamientos políticos de oposición a la austeridad tienden a incrementar su acción política subvirtiendo las condiciones espaciotemporales que la austeridad procura imponer.

Palabras clave: austeridad, ideología política, teoría social, trabajo

\section{Social theory of austerity: a critique to the process of precariousness}

The aim of this article is to develop an interpretation and an understanding of the politico-social phenomenon of austerity, which has been developed in Portugal and in other European countries since 2008, as a social regime based on precariousness. Two complementary objectives are addressed: to characterize this process as a social regime of precariousness considering its structural and existential conditions, namely its space-time structures; to identify the political and economic trends by which these conditions were introduced and developed, involving profound changes on the population's ways of life. The forms of deinstitutionalization resulting from the austerity programs and their impact on a set of social spheres will also be analyzed: such as the depreciation and devaluation of work, the uncertainty of the spatial-temporal experience, the exercise of a specific rationality in the context of human action. Finally, it is shown how political positions opposing austerity tend to ground new forms of political action by subverting the spatiotemporal conditions that austerity seeks to impose.

Keywords: austerity, political views, social theory, work 


\section{A austeridade como política de desenho social}

Na sequência da grave crise financeira de 2008, a palavra austeridade entrou no discurso político à escala global, sobretudo no espaço europeu. As políticas keynesianas de investimento público inicialmente adotadas na União Europeia como reação imediata à crise nascida nos EUA rapidamente foram postas de lado em favor de uma viragem em direção ao que se tornou habitual designar por programa de austeridade ou, ainda, por políticas de austeridade. O momento desta retomada da palavra austeridade é bem evidente, tendo, por exemplo, sido escolhida em 2010 como a palavra do ano do Merriam-Webster's Dictionary, depois de, no ano precedente, o líder conservador britânico David Cameron ter vaticinado a entrada numa nova idade da austeridade. Procurava-se assim retomar, através de uma deslocação de contexto de uso, um vocábulo oriundo de um âmbito valorizado moralmente, relacionado com a escolha de uma atitude ou modo de ser apreciado. Esta retomada da palavra austeridade em termos políticos certamente procurou beneficiar das suas conotações mais apreciativas, como a seriedade, o autocontrolo e a parcimónia da pessoa austera. Apesar deste estouro de usos políticos da palavra austeridade desde 2009, políticas de austeridade estão referenciadas desde pelo menos John Locke (BLYTH, 2013) e, no contexto da tradição francófona, também desde a emergência da classe burguesa francesa que, desprovida dos privilégios de nascimento, deveria justificar o seu estatuto burguês pela assunção de uma condição austera para o seu quotidiano (SARTRE, 2002 [1960]).

Do ponto de vista das políticas económicas, a austeridade pode ser entendida como uma ou mais de um conjunto de políticas possíveis que visam corrigir uma situação de défice reiterado e, consequentemente, de aumento imparável da dívida pública e/ou da dívida externa, através de uma baixa forçada do consumo, privado ou público. Esta baixa de consumo, sendo o denominador comum das políticas de austeridade, é alcançada ou por mudanças na estrutura dos gastos públicos, nomeadamente por meio de cortes na despesa pública, dominantemente na despesa relacionada com as funções sociais do Estado, repercutindo numa baixa do consumo dos seus beneficiários, ou por uma alta nos impostos, onerando o consumo e, simultaneamente, incrementando a receita pública.

De acordo com este entendimento, o conceito político-económico de austeridade designa menos uma política de contenção da despesa ou de controlo orçamental do que a maneira como tal contenção ou controlo é alcançado, a saber, pela transmissão do esforço e dos encargos da correção do desvio à sociedade e aos seus modos de vida, forçadamente modificados através dos meios que a política de austeridade impõe. Por essa razão, o conceito de austeridade neste novo contexto não pode ser simplesmente classificado como uma política orçamental ou mesmo uma política 
económica. Dizendo obviamente respeito a ambas, há que frisar bem que a sua alavancagem é essencialmente social (FERREIRA, 2012). À luz desta consideração, propomos classificar os programas de austeridade como uma política económicoorçamental de desenho social. Consequentemente, enquanto política de desenho social, a austeridade deve pertencer à esfera dos fenómenos político-sociais.

O objetivo central deste artigo é obter uma compreensão deste fenómeno políticosocial da austeridade, vigente em alguns países da Europa, nas suas relações com a instauração de um regime social de existência precária. Este objetivo compreende dois objetivos parciais: por um lado, caraterizar o regime social da precariedade nas suas condições existenciais mais estruturais, designadamente as suas condições espaciotemporais; por outro, identificar os meios político-económicos pelos quais essas condições puderam ser instauradas, a partir de modificações politicamente determinadas da vida social. A articulação destes dois objetivos proporciona uma compreensão em profundidade da austeridade, desde o nível das políticas até os seus efeitos sociais e destes até o nível existencial.

Com estes objetivos em vista, o artigo desdobra-se em várias secções que procuram dar conta desses diferentes planos ou estratos, que proporcionam uma compreensão em profundidade da austeridade. Depois da fixação da austeridade como fenómeno político-social, uma primeira secção avalia e identifica dois grandes modos pelos quais a austeridade se materializa do ponto de vista das políticas económicas, salientando-se a novidade de um fenómeno de desinstitucionalização nos países do Sul da Europa, sobretudo desde a implementação de programas de austeridade. Uma segunda secção interpreta a depreciação precarizadora da atividade do trabalho à luz de uma retoma do conceito polanyiano de desincrustação, agora do trabalho face ao mercado, já de si desincrustado. Uma terceira secção expõe as modificações que a austeridade traz à vivência espaciotemporal, e as duas secções subsequentes avaliam as consequências que dessa modificação se seguem para o exercício da racionalidade no contexto da ação humana. Uma última secção faz de algum modo a prova real desta compreensão da austeridade, ao mostrar como posicionamentos políticos que movem oposição à austeridade tendem a fundar a sua ação política precisamente movendo oposição e subvertendo as condições espaciotemporais que a austeridade procura impor.

\section{A implementação da austeridade: das políticas de liberalização às políticas de desinstitucionalização e precarização}

À semelhança do que aconteceu com os países em vias de desenvolvimento que foram intervencionados, ao longo das últimas décadas, por instituições internacionais, como o Fundo Monetário Internacional (FMI) ou o Banco Mundial, 
Portugal está, neste momento, a sofrer uma brutal reconfiguração da sua economia e sociedade, tendo por base o princípio da liberalização, cujos eixos foram definidos naquilo que ficou conhecido como o Consenso de Washington.

Este princípio geral defende o fim da interferência do Estado nos mercados financeiros e nos mercados de capitais e a eliminação das barreiras comerciais. Isto implicou a liberalização do comércio e a remoção da maior parte das barreiras protecionistas; a liberalização e a desregulação dos mercados de capitais; a privatização da maior parte dos setores da economia (STIGLITZ, 2004; HARVEY, 2011). No entanto, para além destes três mecanismos que se aplicaram bruscamente em muitos países situados no hemisfério sul, a agenda que atualmente é imposta aos países europeus do sul da Europa contempla outras valências que passam distintamente por processos de desinstitucionalização (VELOSO; CARMO, 2012).

Esta desinstitucionalização carateriza-se, no essencial, por uma política que se serve da administração pública para emular as próprias instituições e sistemas do Estado, com o intuito fundamental de criar mercado para os privados. Ao autodestruir-se em termos institucionais, o Estado abre espaço para novos mercados e oportunidades de negócio, por via da privatização e da apropriação por parte dos particulares dos sistemas e serviços sociais de provisão pública (saúde, educação e segurança social).

É importante notar que muitos dos países subdesenvolvidos que sofreram as consequências sociais e económicas das políticas liberais não detinham, na altura, sistemas de proteção social consolidados e de cariz universal, assentes em instituições públicas que constituíam o designado Estado social, nem leis laborais suficientemente abrangentes que permitissem uma proteção efetiva do trabalho e dos direitos laborais associados. Daí que o enfoque, nessa primeira geração de intervenções, tivesse estado dominantemente na liberalização dos mercados. Contudo, no contexto da atual crise económico-financeira, os alvos direcionam-se muito particularmente para dois setores preferenciais: por um lado, o desmantelamento do Estado social através da sua desinstitucionalização; por outro, a flexibilização e liberalização do mercado de trabalho, por meio de políticas de precarização.

É esta a equação primordial da atual política, que produz (e continuará a produzir) consequências profundas e dificilmente reversíveis, pelo menos a médio prazo, na economia, no mundo do trabalho, mas também nas estruturas sociais e de classe. Como tem sido demonstrado por recente análise sociológica (CARMO, 2013), Portugal, para além de ser um dos territórios mais desiguais da União Europeia e da Organização de Cooperação e de Desenvolvimento Económico (OCDE), continua a ser um país marcado por uma dualidade estrutural entre as classes mais privilegiadas e as classes trabalhadoras. Esta tenderá a acentuar-se 
com a continuidade das atuais investidas às designadas classes médias, que visam a redução do seu rendimento disponível e à retirada quase completa dos benefícios sociais que usufruem legitimamente.

As classes dominantes - detentoras dos rendimentos de capital (financeiros, grandes empresários) e/ou monopolizadoras do controlo organizacional (gestores, diretores e administradores) - não só tenderão a melhorar a sua já privilegiada situação económica e social, como verão reforçadas as suas forças e relações de poder (STIGLITZ, 2012; PIKETTY, 2014). A consequência lógica do projeto político de desinstitucionalização revela-se na inevitável 'remercadorização' de muitas das funções sociais e económicas do Estado. Na verdade, a 'remercadorização' é a face mais expressiva de uma concreta política de classe, pela qual são incrementados os interesses da elite, ao mesmo tempo que se fragilizam as situações socioeconómicas das camadas intermédias e se vulnerabilizam ainda mais aqueles que se encontram em situação de precariedade social e económica, por via dos cortes no rendimento disponível, do aumento do desemprego, da redução dos direitos laborais e outros, da pressão para a emigração etc.

Portugal levou vários anos de intervenção (particularmente entre 2010 e 2015) e pode dizer-se que, durante este período, se tornou uma espécie de laboratório da agenda neoliberal, congeminada entre as instituições europeias, o FMI e o governo, cujos objetivos fundamentais passam precisamente por remercadorizar estes setores: de um lado, o recuo do caráter universalista dos sistemas de proteção social e dos serviços públicos, assim como a privatização das poucas empresas públicas que ainda restam; e, do outro, a precarização do trabalho e a redução dos seus custos, acompanhada por uma desqualificação a prazo dos recursos humanos.

A partir da identificação deste conjunto de políticas gerais que têm constituído os meios para a instauração do estado de austeridade, procederemos a uma avaliação das modificações causadas pela austeridade em três dimensões estruturais da organização das sociedades - o trabalho enquanto atividade social produtiva, a vivência social da temporalidade e, por fim, a própria racionalidade prática dos membros da sociedade. Em todas estas três dimensões, surpreendemse transformações muito súbitas e bastante profundas, com custos de vária ordem, designadamente em termos de empobrecimento económico e social.

\section{Austeridade como dupla desincrustação do trabalho}

Com a generalização da economia de mercado e a sua interferência em diversos setores da sociedade, o mundo do trabalho e as respetivas relações laborais sofreram uma alteração profunda: transformaram-se em mercadoria. Este dado foi demonstrado por autores tão distintos como K. Marx ou K. Polanyi. Segundo este 
último, "as mercadorias são empiricamente definidas como objetos produzidos com vista à venda no mercado, e os mercados são, cada vez mais, definidos empiricamente como contratos efetivos entre compradores e vendedores" (PolANYI, 2012 [1944], p. 214). Em seu entender, o trabalho significa a atividade humana que acompanha a própria vida e que não foi produzida para venda. Esta observação estende-se a outros dois elementos: a terra e a moeda. Nenhum destes três elementos foi inicialmente produzido para venda, daí que a sua apropriação, como se de mercadorias se tratasse, ser intrinsecamente fictícia.

$\mathrm{Na}$ verdade, foi por meio da naturalização desta ficção que se deu a grande transformação, caraterizada, pelo autor, por intermédio da noção de desincrustação, que significa a autonomização dos mercados face à restante economia e a sua consequente preponderância em relação aos diversos setores da sociedade humana. O mercado não só se desincrustou da sociedade e da economia como se impôs enquanto força dominante e, de certa maneira, coerciva. A este respeito Polanyi demonstrou que, até o século XIX, a economia esteve sempre incrustada na sociedade, ou seja, o sistema económico era dirigido por motivações não económicas (sociais, culturais, simbólicas) e por instituições de índole comunitária. Como refere o autor, "até o nosso tempo, não existiu uma só economia colocada, ainda que apenas em princípio, sob o controlo dos mercados. [...] Embora a instituição de mercado fosse bastante comum desde os finais da Idade da Pedra, o seu papel foi sempre subordinado no interior da vida económica" (POLANYI, 2012 [1944], p. 175).

Dada a conjuntura atual de profunda crise económico-financeira, as consequências morais e políticas a retirar desta tese ressurgem com particular veemência. Na verdade, do ponto de vista moral, os três elementos em causa detêm uma importância que ultrapassa a mera dimensão material e instrumental. Por exemplo, a natureza é um recurso supremo para a continuidade da humanidade e não deve ser lidado como se tratasse de uma simples mercadoria. O mesmo se aplica ao trabalho; este detém um valor supremo para a vida humana que ultrapassa largamente as contingências resultantes da venda e da compra de forças produtivas. Pois, como nos diria Marx, umas das características mais marcantes do sistema capitalista é a de transformar a força de trabalho numa mercadoria (MARX, 1981 [1891]), as relações sociais e comunitárias tornam-se assim em relações de mercado. Do ponto de vista político, Polanyi defende que estes elementos não podem depender exclusivamente das lógicas dos mercados. Pelo contrário, o Estado detém aqui um papel de equilíbrio fundamental que passa pela regulação e proteção social e económica. Embora não utilize o conceito, trata-se, no fundo, de institucionalizar pela via do Estado social uma efetiva desmercadorização das relações sociais (ESPING-ANDERSEN, 1990).

O processo de transformar o trabalho numa mercadoria tornou-se numa realidade bem concreta, expressa no modo como este é determinante para a 
organização do quotidiano. Para parte considerável das pessoas, o trabalho é uma atividade social e económica central, cuja remuneração garante, ou deveria garantir, a manutenção de uma subsistência condigna. Mas, para além disso, é uma atividade que pode (e deverá) preencher o indivíduo de outros tipos de valor acrescentado, designadamente, de ordem mais subjetiva e intangível (intelectual, criativo e até afetivo). O trabalho detém um valor intrínseco que transcende em muito a sua simples dimensão instrumental. Por isso, mesmo que mantenha um vínculo com as necessidades de obtenção de um rendimento, não esgota nesta captação de rendimento toda a sua motivação, nem sequer tem de ter nela a sua principal significação.

Contudo, considerando as alterações que se desenrolam neste contexto de profunda austeridade, o trabalho está a sofrer um processo acentuado de desvalorização económica e social, evidenciado pela compressão e redução dos rendimentos provenientes de parte substancial dos salários; pela retirada de muitos direitos adquiridos e universais que contribuíam para a proteção parcial face às tendências de 'remercadorização'; pela consecutiva precarização das condições laborais e contratuais; pelo aumento galopante do desemprego etc. Dito de uma forma mais contundente, parece-nos inegável que, mesmo enquanto mercadoria, o trabalho está a perder valor em favor de outras atividades e fontes de rendimento. Embora esta evolução já venha de trás, ela sofreu uma aceleração (irreversível?) devido à presente crise económico-financeira.

Esta desvalorização é relativamente transversal, ocorrendo nas mais diversas populações e grupos sociais: nos qualificados e nos menos escolarizados, nos jovens e nos mais velhos, nas mulheres e nos homens... Trata-se de uma espécie de dupla desincrustação, em que o trabalho passa a estar cada vez mais arredado dos próprios mercados, tornando-se cada vez mais vulnerável. De uma certa maneira, podemos dizer que, para além de continuar a evoluir, o processo reconfigurou-se, pois, apesar de significar uma atividade primordial e marcadamente humana, o trabalho não só se foi 'mercadorizando', como, nesta última fase do capitalismo, tende a perder todo seu valor intrínseco, incluindo mesmo o seu valor económico. Esta dissonância entre o significado valorador do trabalho, como atividade humana autorrealizadora em interação com o mundo e a sociedade, e a sua expressão concreta, como elemento duplamente desvalorizado, leva a que este seja, neste momento, um dos principais veículos de desigualdade e precariedade social.

\section{A austeridade como temporalidade confinada ao instante presente}

Na sua generalidade mais ampla, a experiência do tempo na modernidade é bastante bem conhecida. Dispõe-se num contínuo linear, seja no plano da vida temporal de cada sujeito humano, seja no plano da vida histórica das 
comunidades. E em ambos estes planos, a relação concreta com o tempo linear estrutura-se como uma alternativa entre maior ou menor emancipação. No caso da temporalidade dos indivíduos, a consciência moderna assumiu a vida completa como coincidindo com os limites do projeto pessoal de existência, o que pressupôs a possibilidade de um controlo, através da recursividade e portanto da previsibilidade, da vida completa. Não fosse o infortúnio, até mesmo o destino, e, em condições de normalidade, este controlo relativo sobre o seu próprio trajeto temporal indicaria a emancipação do sujeito moderno. No caso da História, o tempo das comunidades na modernidade dispôs-se como uma seta que tem o progresso como motor em direção a um fim orientador (AMIN, 2010 [1988]). Entre ambos os planos temporais estabelecem-se vínculos, podendo considerarse o progressismo, no seu sentido mais amplo, como um impulso de orientação das comunidades na História em direção a uma materialização da emancipação dos sujeitos modernos. Isto significa que a modernidade que privilegiou a ideia de emancipação relacionou-se com o tempo estimando sobretudo a sua dimensão futura (KoSELLECK, 2004 [1979]; HABERMAS, 1990 [1985]).

Esta constância das relações temporais não era menos evidente nos pressupostos do capitalismo, como modo de produção que mais se impôs na modernidade. Com efeito, os ciclos de reprodução do capital são motivados por expetativas de amplificação de diferenças de capital iniciais, e, por isso, pressupõem uma História como continuidade estável de acumulação de capital. Como sucedia com a ideia de progresso, há uma dimensão aditiva, de acumulação, que permite calcular face ao tempo anterior o que mais se alcançou numericamente. Contudo, e diversamente do caso do progressismo emancipatório, a acumulação do capital estima sobretudo a dimensão passada, que visa projetar no futuro. Seja do ponto de vista da teoria marxiana da acumulação original ou primitiva (Ursprüngliche Akkumulation), com antecedentes na ideia de acumulação prévia de Adam Smith, seja do ponto de vista da evidência empírica do papel da herança na estruturação da divisão do capital ao longo da História, podendo falar-se de uma "sociedade de herdeiros" (PIKETTY, 2014), é a dimensão do passado que se torna orientadora do sentido como o tempo é vivido.

Assim, entre o progressismo emancipador e o processo de reprodução do capital compreende-se uma oposição também por esta oposição nas maneiras de relacionamento temporal - respetivamente, uma orientação que privilegia o futuro versus uma orientação que privilegia o poder orientador do passado. Se ambas têm podido conciliar-se historicamente, tem sido sem dúvida na medida em que a reprodução do capital tem conseguido historicamente assegurar crescimento suficiente para acomodar realizações emancipatórias mau grado a amplificação de diferenças. Mas, mais estruturalmente, a conciliação tem sido 
possível porque partilham o mesmo tipo de vivência temporal estável em que o passado e o futuro estão ao alcance de um presente humano. Com efeito, esta continuidade estável entre passado, presente e futuro que caracteriza a vivência do tempo na modernidade tanto assegura a possibilidade de uma conceção de tempo acumulativa indispensável à acumulação de capital, como assegura a possibilidade de uma conceção de História como progresso paulatino, em que às conquistas civilizacionais se somam outras.

Aliás, e contra as aparências mais imediatas, esta organização do tempo como permanecendo ligado numa mesma continuidade manejável, suscetível de acumulação como de progresso, é também, segundo John Gray, a base das conceções apocalípticas da História. Como nota o autor, "as teorias do progresso que afirmam rejeitar qualquer crença num estado final de perfeição acabam, numa observação mais atenta, por reter a ideia de que a história é uma luta entre as forças do bem e do mal" (GRAY, 2008, p. 39). A ideia de que nos abeiramos do fim do mundo teria pelo menos em comum com a ideia de que vamos avançando e progredindo o mesmo pressuposto de que, de uma maneira ou de outra, é pela História que nos salvamos. Este ponto de vista, se não ganha respaldo, pelo menos ajuda a compreender a atmosfera apocalíptica que, com bastante facilidade, se foi impondo à modernidade muito na forma de uma pós-modernidade que assistiu à afirmação, sobre os escombros da guerra fria e do conflito ideológico, de um tempo pós-político, sem genuínas clivagens nas representações disponíveis, a que se aliou uma sucessão de fins, especialmente o da História, que, começando de forma célebre na tese de Fukuyama de 1992, se prolonga, já por duas décadas, justificando que o assunto deixe de ser o da problematização de um fim dos tempos, mas sim a problematização de como viver nesse tempo do fim dos tempos (ZIZEK, 2011).

Esta conceção linear do tempo que dominou a modernidade encontra-se hoje profundamente perturbada. Tanto no plano da vida histórica das comunidades, como no da vida temporal de cada sujeito humano, há uma modificação drástica da experiência do tempo. Trata-se de uma transformação profunda e rápida da experiência do tempo, que não é acompanhada por uma modificação das representações sobre a mesma, disparidade que explica o surgimento de uma reação cataclísmica sobre a experiência do tempo e uma interpretação dela a partir de ideias apocalíticas, ainda oriundas, como aludimos acima, de um quadro conceptual comum à modernidade.

A primeira alteração profunda face à modernidade é a deterioração da condição do humano como uma condição de autonomia, designadamente no que diz respeito às relações do humano com o seu tempo, seja no plano dos indivíduos, seja no plano das comunidades. No lugar dela, vai sendo afirmada uma heteronomia que 
recusa a cada vez mais domínios relevantes para as vidas humanas a capacidade de fazer escolhas e de as assumir, deslocando para um horizonte fora do alcance das escolhas humanas a realidade que determina o que as escolhas deixaram de poder determinar. Este horizonte que transcende a autonomia e torna fúteis as suas pretensões modernas ganha múltiplas manifestações. É, por exemplo, esse o sentido que leva à crescente vindicação de que a necessidade económica remove direitos à escolha democrática sobre o futuro, esvaziando o domínio da economia política ou, ao menos, conduzindo-o a uma rigidez que apenas deixa perspetivar uma escolha demasiado drástica, entre a plena aceitação ou a total recusa. É também, e de forma consistente, o fenómeno já bem evidenciado de que as democracias desviam-se para um tipo de regime pós-democrático ( $\mathrm{CROUCH}, 2004)$, democracia do espetáculo, essencialmente ligada a aspetos performativos, subordinando e relativizando a importância de escolhas de fundo político.

Este processo de heteronomização que sucede no plano da vida das comunidades e mesmo de Estados políticos, cuja soberania vem assim cada vez mais circunscrita, repercute na capacidade de projeção do futuro a partir do contínuo temporal. A apreensão linear do tempo tende a decompor-se nas dimensões do passado, do presente e do futuro, como dimensões essencialmente alheias umas às outras. Com efeito, o futuro é apreendido cada vez mais como um futuro incompreensível a partir de uma ordem de sentido e de ação presentes, e o presente, por seu turno, tende a ser apreendido como um resultado completamente determinado por um passado e grandemente impotente perante o futuro, mesmo o futuro próximo. 0 tempo aberto de uma História com futuros possíveis que não sabemos determinar por completo, mas sabemos prever e sabemos incluir num campo de sentidos e de ações, dá lugar a um tempo que, na sua transcendência exacerbada, se fecha à compreensão e à própria ação. Em suma, heranças exacerbadamente pesadas e futuros exacerbadamente fugidios alienam as comunidades do seu tempo, limitando, se não mesmo anulando, a possibilidade de se posicionarem face a ele e a possibilidade de assumirem assim a sua contemporaneidade.

Pode mesmo falar-se de uma ausência de contemporaneidade nos tempos que vivemos hodiernamente, tensão ou paradoxo muito bem captados por uma afirmação de Nietzsche nas Considerações Intempestivas, e retomada por Agamben em $O$ que é o contemporâneo?, de que "verdadeiramente contemporâneos, verdadeiramente do seu tempo, são aqueles que não coincidem perfeitamente com ele nem se ajustam às suas exigências" (AGAMBEN, 2008). Ora, se a austeridade pôde ser descrita nos termos de uma vivência do tempo social, é exatamente nos termos de uma coincidência forçada do presente das comunidades com o seu presente mais imediato. 
No plano dos sujeitos considerados individualmente, constata-se a mesma heteronomização do tempo, desumanizando-o, que se verifica nas comunidades. Assiste-se a uma redução e inversão das expetativas de projetos de vida, a partir de um horizonte futuro que se tornou normalmente incerto e imprevisível. Aliás, em perfeito contraste com uma tradição de austeridade das ordens monacais (FRANCO, 2011), cujo funcionamento assentava numa regra que materializa uma previsibilidade precavida, a austeridade do austerismo hodierno cria as condições mais favoráveis a uma exposição desguarnecida, inteira e deliberadamente à mercê do imprevisível (BARATA, 2014).

Um primeiro e primacial nível desta heteronomização do tempo sucede no trabalho, enquanto atividade humana social mais universal. Embora a precariedade não possa ser reduzida à questão laboral, não há qualquer dúvida de que a situação decorrente do contrato de trabalho é o critério fundamental para a determinação daquilo que pode ser considerado como uma situação precária. É claro que, do ponto de vista contratual, a precariedade assume muitas variantes, que vão desde a inexistência de qualquer tipo de contrato até à estipulação dos contratos a prazo ou a termo certo. Contudo, apesar das variantes, em todas estas situações persiste um denominador comum temporal: a incerteza perante o previsível depois-depois de o contrato expirar, depois de o projeto findar, depois de a tarefa se esgotar.

A incerteza face ao 'depois de', do qual ainda não se descortina o que possa vir a seguir, significa a redução do horizonte temporal com autonomia a um presente quase imediato. Esta concentração de todo o tempo autonomamente controlável no presente mais próximo, dele desprendendo o futuro e o passado, é simplesmente a contraparte da heteronomização de todo o tempo com exceção desse presente instantaneizado. Perante esta "instantaneização" do tempo social, o futuro projetável parece esvaziar-se como uma espécie de buraco negro onde a improbabilidade adquire um sentido quase absoluto. Na verdade, o que transforma a precariedade numa realidade que extravasa a questão laboral, e entra pelo resto da vida adentro, deriva precisamente desta ideia de que a incerteza se torna o único dado previsível, com que se tem inevitavelmente de contar. Ou dito de uma forma mais perentória: a precariedade é incerteza tomada como certa. Não se trata, por isso, de um mero imponderável que pode ou não acontecer, ou que tem a mesma possibilidade de se concretizar ou de nunca vir a ser realidade. Pelo contrário, a precariedade transforma a imprevisibilidade num dado absoluto, que naturaliza a heteronomia temporal, face à qual não resta outra alternativa senão a conduta essencial ou dominantemente reativa.

A reação passa em grande medida pela capacidade de antever múltiplos cenários, que no fundo não são mais do que hipóteses e tempo, sobre o que vai suceder a seguir ao 'depois de'. Segundo Mead, a construção da temporalidade na sociedade 
moderna consubstanciava-se na projeção de horizontes de tempo nos quais se previam hipóteses prováveis para projetos e ações futuras. No entanto, no contexto de uma situação continuada de precariedade, a ação deixa de compreender um significado prospetivo, circunscrevendo-se ao meramente reativo. Isto é, já não é possível delinear uma hipótese provável para o futuro, sobre a qual se constitua um plano ou projeto de ação, e uma gestão do risco, mas apenas averiguar uma amplitude de alternativas, por vezes contraditórias, de atividades ou de tarefas passíveis de serem executadas que impeçam a incerteza de se impor enquanto dado absoluto que tende a apoderar-se de tudo o resto. Desta forma, viver em precariedade representa uma reação constante contra a inevitável certeza do incerto, sem a possibilidade de estabelecer um plano ou projeto de ação. Significa, simultaneamente, um imenso desgaste social e emocional que se transfere para diversos setores da vida quotidiana.

Analisar a precariedade a partir das dimensões subjetivas implica fazer uma interpretação sobre o modo como se constroem as suas temporalidades e como estas entram em rutura com as formas modernas de construção social do tempo (STANDING, 2014). Como foi referido, a condição precária estabelece-se numa permanente reação contra a inevitabilidade da incerteza. Para esta, o futuro apresenta-se quase sempre como um risco, nunca se sabe muito bem o que pode vir a acontecer (CARMo; CANTANTE; ALVES, 2014). O futuro é um dado imprevisível perante o qual as expetativas mais contraditórias podem ser simultaneamente ponderadas. Ou seja, o futuro abre-se de tal maneira, como um enorme buraco, que torna impraticável a estipulação de um determinado horizonte temporal a partir do qual se constrói um quadro minimamente estável de expetativas. Ao abrir-se tanto, o futuro deixa de ser uma possibilidade linear, uma hipótese de tempo, segundo a conceção de Mead (1932), e passa a ser uma amálgama de hipóteses desarticuladas que podem apontar para sentidos contraditórios. Assim, ao abrir-se a tantos cenários, o futuro perde-se enquanto construtor de horizonte de expetativas e esfuma-se no próprio tempo, como se o encarcerasse num incontornável presente.

De facto, a situação de precariedade encalha o sujeito no presente: o futuro dissipa-se e o passado de pouco serve. O agora que é fugaz apresenta-se como o único recurso disponível que se tem como seguro. Este é reincidente e confrontanos perante a necessidade de ter sempre de atuar, de ir em frente. A precariedade impele os indivíduos a não cessarem de reagir. Mas não se trata de uma reincidência em que se retoma parte substancial dos gestos anteriores repetidos ciclicamente. $A$ precariedade impõe o agora desligado daquele que o antecedeu e, nesse sentido, desritualiza o curso do dia-a-dia, como se a repetição se degenerasse dos seus próprios ciclos (transformando-se em dia/a/dia). A precariedade quebra com o 
conforto relativo das rotinas, substituindo-o pelo desconforto do tempo sempre presente. Só nesta medida ele é reincidente: não por repetição, mas por imposição de um agora desligado do antecedente.

Assim, para além de transformar a imprevisibilidade numa certeza, a precariedade desritualiza as rotinas do tempo presente, descontinuando tanto os trajetos pelo espaço-tempo, como os gestos que Ihes estão associados. Este dado representa uma alteração muito profunda nos modos de organizar o quotidiano, característicos das sociedades modernas, como bem demonstraram diversos sociólogos (GIDDENS, 1989; GoffMAN, 1985 [1959]). Para estes autores, a vida social era organizada a partir de fatores de ritualização da ação e da interação social, que se expressavam na reactualização de gestos e condutas pré-estabelecidas que se repetiam de dia para dia. A generalização da precariedade quebra com o tempo recursivo do quotidiano e transforma-o num tempo desritualizado, mais suscetível ao risco e à imprevisibilidade.

\section{Austeridade como hegemonia da razão instrumental}

Segundo Max Weber (1983 [1921]), com a progressão e generalização do sistema capitalista, a racionalidade instrumental, que se orienta para a realização de fins determinados, tende a tornar-se dominante nas sociedades contemporâneas. Trata-se de um tipo de racionalidade que dá primazia ao caráter instrumental da ação, no sentido de maximizar as maiores vantagens possíveis para se atingir os resultados antecipados. Deste modo, a razão instrumental detém um significado eminentemente estratégico que valoriza obtenção de ganhos particulares e individuais. Este tipo de racionalidade não valoriza a construção de entendimentos mútuos resultantes do processo de negociação recíproca entre as partes. Pelo contrário, trata-se de uma racionalidade que concebe o processo como um meio para atingir um fim pré-estabelecido. Ou seja, o processo não é visto como um meio em si a partir do qual se poderá chegar a resultados não esperados ou imprevisíveis resultantes da interação entre as partes, mas como um meio estabelecido exclusivamente para se obter certos resultados esperados por cada uma das partes.

Os mercados representam a arena primordial em que se desenvolvem os processos decorrentes da razão instrumental. Na verdade, estes propiciam o jogo entre concorrentes, por via dos quais se mobilizam estratégias particulares de modo a retirar o maior usufruto das suas ações específicas. Todavia, uma das características fundamentais do capitalismo foi a de ter alargado os mercados a outros setores da vida social. Estes processos têm sido analisados por diversos 
autores como Polanyi ou Habermas (1990 [1985]). Este último retoma uma conhecida distinção analítica entre o mundo da vida (Lebenswelt) fenomenológico - que se refere aos significados e valores partilhados pelos indivíduos, aos processos comunicativos e aos aspetos mais rotinizados da vida social - e o Sistema - que se refere às dimensões estruturais e funcionais que condicionam a ação, designadamente ao nível do económico (com primazia para as transações financeiras monetárias) e do político (por via das relações de poder). Segundo o autor, a razão instrumental é determinante na organização e funcionamento dos sistemas. Enquanto o mundo da vida se organiza por meio da ação e razão comunicacional que detêm um caráter social e interpessoal orientado para alcançar o entendimento mútuo (BAERT; SILVA, 2014).

Ora, segundo Habermas, com o aprofundamento da modernidade, os imperativos do sistema tendem a instrumentalizar o mundo da vida. Aquilo que o autor designa como a colonização do mundo vida. Estes processos de colonização são muito diversificados e têm sido abordados por vários autores desde pelo menos o século XIX. A este respeito, Marx foi dos primeiros autores a identificar os processos de mercadorização das relações de trabalho e a sua interferência nas dimensões do mundo social.

Do nosso ponto de vista, pode ser interessante analisar os fundamentos da austeridade como processo de precarização da vida social tendo por base esta distinção analítica proposta do Habermas. Isto é, podemos entender a austeridade como um veículo de radicalização das formas de colonização do mundo da vida definidas pelo autor germânico. Quer isto dizer que a austeridade acentua os processos de colonização do sistema económico e financeiro nos diversos setores da vida social e até pessoal.

Um dos sintomas associados a esta forma de radicalização passa pela generalização do tipo de razão instrumental nas esferas do quotidiano e da vida privada. Por exemplo, a ênfase atribuída ao mérito decorrente do esforço individual que vive em consonância com os recursos que supostamente pode produzir, não vivendo, por isso, acima das suas possibilidades, é uma derivada muito eficaz relativamente à lógica instrumental de conceber a vida social. Nesta perspetiva da colonização do mundo da vida, a austeridade representa um catalisador que impõe às formas de organização social e comunitárias lógicas instrumentais de ação que dão primazia ao interesse individual de atingir objetivos particulares, em detrimento do interesse coletivo resultante da concertação entre as partes. A racionalidade que valoriza a obtenção estratégica de determinados fins em função do mérito e das possibilidades individuais, tende a romper com outras formas de relacionamento social que, por exemplo, incorporem lógicas de ação coletiva. 


\section{A precariedade como suspensão da racionalidade prática}

Se a austeridade se mostra uma estratégia de racionalidade instrumental, podendo bem ser enquadrada entre a diversidade de modos de colonização do mundo da vida, já a precariedade parece afrontar a própria possibilidade do exercício de uma racionalidade prática, entendida esta como faculdade humana de deliberação reflexiva sobre a acção. Desde logo porque desloca o questionamento do plano das estratégias - em que a austeridade é concebida como uma escolha, mesmo que uma escolha muito forçada, que os sujeitos fazem - para o plano da situação efetiva de precariedade que é vivida como realidade encontrada e não escolhida. Significa isto que as questões sobre racionalidade já não se colocam nos termos de saber que racionalidade se adota, instrumental ou não, mas nos termos de saber que condições de possibilidade enformam a racionalidade num quadro de existência em precariedade.

Não sendo uma escolha para os que a sofrem, a precariedade é, contudo, dotada de uma intencionalidade. É resultado de políticas concretas e das valorizações por estas animadas. A intencionalidade da precariedade é instalar um horizonte de incerteza permanente sobre a própria racionalidade prática dos sujeitos e das comunidades em que se inserem. De forma mais abrangente, esta intencionalidade participa de uma visão das condições de existência humana como devendo dispor-se a uma ordem de circulação e mudança constante. A normatividade aqui mencionada pode ser interpretada como valorização da correspondência com uma representação da realidade social e humana nos termos de uma permutabilidade universal, que tem na moeda um exemplo evidente, mas também tem no trabalho uma instância. É sobre este pano de fundo mobilista que se recusa a possibilidade de estacionaridade do humano, seja individual, comunitário ou social. Tal não estacionaridade enquadra e faz sistema com a discricionariedade da existência precária, ou seja, de uma condição permanentemente exposta à incerteza e à vigilância intranquila. Por outras palavras, a precariedade exprime para as pessoas nas suas existências de carne e osso o mesmo imperativo «Não pares!» que, antes, se impôs ao dinheiro e ao trabalho.

Este imperativo mobilista baseia-se, contudo, numa profunda e paradoxal tensão com as condições para uma ação em autonomia. A existência precária é tão forçada a não parar, como impedida de se apropriar do seu movimento por meio de escolhas e ações não meramente reativas. É feita mover-se, mas é destituída da capacidade de se mover por iniciativa das suas deliberações, bem como da capacidade de se mover através da consideração de um tempo presente com boa visibilidade para o futuro e para o passado.

Mas, se o sujeito precário não se move no tempo, estando confinado a um presente instanteinizado e, por isso, meramente reativo, já a sua situação espacial 
vê-se constrangida ao imperativo oposto. É esperada a máxima disponibilidade do sujeito precário para se mover em todo o espaço, imperativo mobilista que tem a sua expressão mais notória no aumento dos indicadores de emigração, mas também, a montante, no desenho político de condições mais fáceis de circulação no espaço europeu, ou, ainda, na flexibilização jurídica da mobilidade do posto de trabalho. Este paradoxo entre imobilidade temporal e mobilidade/circulação espacial exprime o que é o regime da precariedade, nas suas condições existenciais mais básicas. Sob estas condições espaciotemporais, a existência precária sujeitase à mudança súbita e iminente, permanentemente disponível para a mudança, sem direitos de enraizamento, mas também sem direitos de projetar um outro enraizamento e agir em vista de uma mudança provida de significado. Na realidade, está aqui em causa uma alienação do sujeito humano face à sua própria ação, cada vez menos determinada pela sua capacidade de deliberação, com base em razões para agir, a partir da sua experiência de estar-no-mundo.

A precariedade traz, assim, consequências profundas à própria ideia de racionalidade prática. À semelhança da busca de rendimento que estimula o mobilismo do capital, a precariedade é açulada pela imprevisibilidade, a inconstância e a sobrepresença de um caos iminente. No entanto, é precisamente a circunstância de desordem ou de falta de reconhecimento de uma ordem que bloqueia o exercício da razão prática, enquanto capacidade humana de decidir, por meios racionais, o que fazer. No limite, não há como enunciar uma razão precária porque enunciá-la é enunciar uma contradição nos termos. Na sua forma pura, a precariedade destitui qualquer padrão, ordem, recursividade ou repetição, que são os pressupostos mais básicos de uma qualquer ideia de racionalidade. Podemos, então, nestes termos, afirmar que as condições de uma existência em precariedade estabelecem-se $a$ priori na incapacitação de uma qualquer racionalidade prática. Decerto, subsiste uma forma de racionalidade que estrutura a ação tendencialmente reativa que resta aos sujeitos. Esta racionalidade, contudo, sendo abstraída de uma qualquer dimensão autopropositiva a partir da esfera de autonomia dos sujeitos, não tem outro respaldo do que a instrumentalidade. O sujeito precário, sendo tendencialmente despromovido, nas suas interações sociais, à condição de ponto nodal de uma rede que não domina, já não pode exercer outra racionalidade do que a dos meios.

\section{A política contra-austeritária e as práticas de re-emancipação}

Face aos impactos da crise financeira e as consecutivas políticas de austeridade que se seguiram a partir de 2010, designadamente nos países do sul da Europa e na Irlanda, sucederam várias movimentações sociais de protesto e de questionamento dos modelos políticos vigentes nestes países, como foi o caso dos Indignados em 
Espanha. Alguns destes protestos decorreram ou foram parcialmente influenciados por outras movimentações ocorridas em diversos pontos do mundo, com destaque para a Primavera Árabe, que abarcou diversos países do Magrebe, ou o Occupy Wall Street, que surgiu nos EUA. Embora irrompessem por diferentes motivos, pode estabelecerse algumas similitudes entre estes vários movimentos. Desde logo, não é muito forçado afirmar que incorporaram forças de autonomização face à inevitabilidade do instituído e aos mecanismos de precarização caracterizados anteriormente.

Segundo a análise do sociólogo Manuel Castells (2013), os diferentes movimentos sociais que eclodiram a partir de 2010 (Primavera Árabe, Indignados, Occupy Wall Street[...]) têm alguns traços em comum, que podemos resumir sinteticamente: superaram a divisão entre identidade comunitária local e rede global de indivíduos; geraram a sua própria forma de temporalidade, entre a imprevisibilidade do dia-a-dia e a projeção de horizontes ilimitados de possibilidades e de novas formas de vida e de organização política; alcançaram a transição da indignação à esperança pela construção de espaços de autonomia caracterizados por práticas de deliberação política e participativa; caracterizaram-se por serem movimentos sem líderes (polarizadores e muito carismáticos), organizados em redes horizontais de relacionamento; caraterizaram-se por serem movimentos altamente reflexivos mas sem agendas predefinidas (com a exceção do derrube de regimes ditatoriais, no caso do Egipto e da Tunísia); apesar de não se oporem ao princípio da democracia representativa, outra constante nestes movimentos foi a de que denunciaram as atuais práticas institucionais da democracia pondo em causa a sua legitimidade

Segundo Castells, formaram-se espaços de autonomia construídos a partir da interação entre as redes de comunicação sem fios e os espaços físicos das cidades (por intermédio da ocupação de praças ou edifícios simbólicos). Desta feita, os movimentos conseguiram ser globais e locais ao mesmo tempo. Em certo sentido, a política voltou a localizar-se na polis, fazendo parte da vida do dia-a-dia, pelo menos durante os meses em que as movimentações aconteceram. A política reentrou assim no mundo da vida por via de uma prática quotidiana sujeita, por um lado, a múltiplas imprevisibilidade e arbitrariedades, mas, por outro, a novas formas de ritualização da ação política vivida em espaços concretos da cidade.

Não é por acaso que muitos destes movimentos assentaram os seus protestos, reivindicações e propostas em ocupações coletivas, mais ou menos prolongadas no tempo, de espaços físicos das cidades (acampamentos em praças, largos, ruas etc.). A prática coletiva de ocupar e subverter os usos do espaço, interrompendo, por vários dias ou semanas consecutivas, as rotinas e disposições habituais, é uma constante destes movimentos, em que o direito à cidade se torna num pressuposto básico do direito a formas alternativas de fazer política (TEJERINA et al., 2013), no sentido definido por H. Lefebvre (2012 [1968]). Deste modo se produziram 
novas espacialidades, reconvertendo as funções e usos habituais de maneira a transformar sítios de passagem e de circulação em locais de fixação. Fixar no espaço a permanência do debate, das assembleias, da co-vivência significa fixar uma temporalidade, ou, dito de outra forma, significa construir um processo histórico. Foi por este intermédio que se produziram espaços de emancipação virados para a projeção de vias futuras de intervenção e de organização social.

Estes movimentos deram ênfase fundamentalmente às modalidades de participação e de deliberação e não tanto à definição pré-estabelecida de fins a atingir. A sua capacidade reflexiva não comportou uma racionalidade de tipo instrumental, mas outros fatores que passam mais pela valorização do processo em si, em detrimento do objetivo último a alcançar. Trata-se de formas de racionalidade que incorporam, ao mesmo tempo, vários mecanismos: comunicacionais (pelo uso intenso das redes sociais e de outras formas de comunicação); internacionais (pela ênfase depositada na organização de assembleias e outros encontros coletivos); processuais (pela necessidade de construir processos de deliberação conjunta e alargada continuados no tempo). Estamos, no fundo, perante múltiplas racionalidades práticas que se congregam e se articulam nos mesmos espaços de ritualização da participação política.

De uma certa maneira, podemos caraterizar estas movimentações como contra-austeritárias na medida em que rompem com muitos dos pressupostos que fundamentam a política de precarização aprofundada pela austeridade. Desde logo, rompem com a exclusividade da razão instrumental e com os processos de colonização do mundo da vida e de suspensão da racionalidade prática. $\mathrm{Na}$ verdade, gera-se uma inversão a partir da qual despontam, no seio do mundo da vida, alternativas de produção reflexiva produzidas a partir do desenrolar dos próprios processos de deliberação. Perante esta capacidade, novas temporalidades são reinventadas coletivamente na medida em que tentam almejar a possíveis horizontes de futuro, construindo, assim, uma autonomia em se mover no tempo que, simultaneamente, se fixa numa determinada espacialidade.

\section{Conclusão}

Procurámos alcançar uma compreensão da austeridade como fenómeno político-social que instaura a precariedade como regime normal de existência social. Verificámos que a implementação da austeridade, sendo politicamente determinada num plano de políticas económicas, visa, em profundidade, uma modificação das condições existenciais da vida social. Tornou-se o modelo de todas as relações laborais, e tornou-se, fora destas, o modelo de existência social mais consentâneo com as condições espaciotemporais que a austeridade visa implementar. 
Estas condições espaciotemporais da precariedade deixam-se exprimir pela seguinte formulação: a exigência de máxima disponibilidade para a mobilidade espacial é conjugada com a imposição da máxima imobilidade temporal. Nestes termos, a precariedade exprime uma dupla impossibilidade. Por um lado, impossibilidade de enraizamento no espaço, designadamente no espaço de uma comunidade, o que permitiria produzirem-se respostas de resguardo face à exposição ao risco permanente e iminente, mas também criar formas organizadas e diferenciadoras de estar em comunidade. Pelo contrário, as lógicas de desenvolvimento comunitário são contrariadas, mesmo impedidas, por uma hegemonia da agência individualizada.

A precariedade requer a cada indivíduo, no movimento de sua disponibilidade absoluta, o arreigamento à sua condição de indivíduo indiferenciado, privilegiada sobre quaisquer vínculos comunitários, até mesmo os de natureza familiar. Mas, a precariedade implica uma segunda impossibilidade de enraizamento e uma segunda consequência solitária, complementares à espacialidade desenraizada e só. A imobilidade num tempo de instantes, sem portas de passagem para um futuro projetável e para um passado ressignificável, vota os indivíduos à impossibilidade de enraizar um projeto de ação nas suas existências. Cumprem-se assim as duas direções do desenraizamento e estranhamento entre o sujeito e um mundo que não poderá assumir como seu. Se a acentuada mobilidade espacial exprime a impossibilidade de enraizar uma existência no mundo da ação, a imobilidade temporal exprime a impossibilidade de enraizar o mundo da ação na existência.

Um segundo conjunto de conclusões inscreve-se numa tentativa de compreensão do que seja o tipo de racionalidade subjacente ao regime de precariedade em instauração. A pergunta sobre se há uma razão precária é particularmente pertinente, não porque se duvide da bastante evidente transição da racionalidade moderna para uma outra instância adequadamente qualificada como precária, mas por estarem ameaçadas as próprias condições de subsistência de uma racionalidade no contexto da hegemonização da precariedade. A razão precária precariza a própria razão. O exercício da racionalidade é possível em todas as circunstâncias com exceção de uma - a ausência de padrões, de recursividade, de repetição. Ora, se há um ideal de padrão da austeridade enquanto ação política instauradora da existência socialmente precária, é precisamente como padrão de segunda ordem de impossibilidade de captação de um padrão. A razão precária representa, então, uma suspensão da própria racionalidade, apenas possibilitando uma metarracionalidade, ou seja, uma racionalização da incapacidade de exercício da racionalidade. Esta suspensão da racionalidade prática, enquanto faculdade humana de refletir e deliberar sobre o que fazer, subtrai ao sujeito precário a capacidade de agir. No lugar da ação, deliberada e conduzida de forma racional e em vista de fins, 
o sujeito precário torna-se sujeito de meras reações, ou seja, de meras respostas de conservação de posição desinscritas de um quadro de finalidades próprias do sujeito. Ao contrário do sujeito que age, e que procura por meio da ação afeiçoar o mundo às suas finalidades próprias, o sujeito que reage simplesmente procura adaptar-se a um mundo sobre o qual não exerce nenhuma forma de domínio. Aliás, incapacitado para o exercício de quaisquer finalidades próprias, o sujeito que reage perde-se no mundo, sem domínio sequer sobre si próprio, consagrado por inteiro ao movimento dos meios entre outros meios. Culmina assim a racionalidade instrumental, que Habermas havia oposto à Lebenswelt, na instrumentalização da própria razão e do seu sujeito para fins inescrutináveis do ponto de vista de uma racionalidade humana autónoma.

A instauração da precariedade é um processo de debilitação desta autonomia humana, em que se destitui, de forma muito concreta, o exercício, nos diferentes planos da vida em comum das sociedades, de os sujeitos se sujeitarem apenas às leis que entre si acordam dar-se a si mesmos. A precariedade exprime, portanto, além de uma profunda modificação da existência social, uma não menos contundente modificação da sociedade enquanto comunidade política democrática.

Contudo, surgiram recentemente movimentos coletivos de reação e de forte questionamento aos processos decorrentes da austeridade. Construíram-se espaços momentâneos de emancipação que se ancoraram na ocupação de praças e ruas das cidades, onde se reinventaram práticas de participação cívica e comunitária. Embora se tivessem esfumado com o decorrer do tempo, estas diversas movimentações criaram um potencial de esperança sobre a possibilidade de uma efetiva transformação social por via da intensificação da participação democrática e cívica. Por este motivo, uma teoria da austeridade satisfatória, depois de lançada a partir de uma teoria social, deve ser prolongada numa teoria política da austeridade que se detenha na elucidação e explicação dos modos por que a precariedade social tem por contraparte política um processo de heteronomização (BARATA; CARMO, 2015).

\section{Referências Bibliográficas}

AgAMBEN, Giorgio.O que é o contemporâneo e outros ensaios. Chapecó, SC: Argos, 2008.

AMIN, Samir. Eurocentrism. Nova lorque: Monthly Review Press, 2010 [1988].

BAERT, Patrick; SILVA, Filipe Carreira da. Teoria social contemporânea. Lisboa: Editora Mundos Sociais, 2014.

BARATA, André. Do austerismo ou do abuso sobre a existência temporal. In: EWALD, Ariane et al. (Orgs.). Subjetividades e temporalidades. Rio de Janeiro: Garamond, 2014. 
BARATA, André; CARMo, Renato. O futuro nas mãos: de regresso à política do bemcomum. Lisboa: Tinta-da-China, 2015.

BLYTH, Mark. Austeridade - a histório de uma ideia perigosa. Lisboa: Quetzal, 2013. CARMo, Renato Miguel do. Portugal uma sociedade de classes: polarização e vulnerabilidade. Edição Portuguesa. Lisboa: Edições 70/Le Monde Diplomatique, 2013.

Carmo, Renato Miguel; CAnTANTE, Frederico; Alves, Nuno de Almeida. Time projections: youth and precarious employment. Time \& Society. v. 23, n.3, p. 337-357, 2014.

CASTELLS, Manuel. Redes de indignação e esperança: movimentos sociais na Era da Internet. Lisboa: Fundação Calouste Gulbenkian, 2013.

Crouch, Collin. Post-Democracy. Cambridge UK: Polity Press, 2004.

ESPING-ANDERSEN, Gosta. The three worlds of the welfare capitalism. Cambridge: Polity Press, 1990.

FRANCO, José Eduardo (Org.). O esplendor da austeridade - mil anos de empreendedorismo das ordens e congregações em Portugal: arte, cultura e solidariedade. Lisboa: IN-CM, 2011.

Ferreira, António Casimiro. Sociedade da austeridade e do direito do trabalho de exceção. Porto: Vida Económica, 2012.

FUKUYAMA, Francis. O fim da História e o último homem. Lisboa: Gradiva, 1999 [1992].

GofFMAN, Erving. A representação do eu na vida cotidiana. 4. ed. Petrópolis: Vozes, 1985 [1959].

GRAY, John. A Morte da utopia e a religião apocalíptica. Lisboa: Guerra \& Paz, 2007. GIDDENS, Anthony. A constituição da sociedade. São Paulo: Martins Fontes, 1989.

HABERMAS, Jürgen. O discurso filosófico da Modernidade. Lisboa: Dom Quixote, 1990 [1985].

HARVEY, David. O enigma do capital e as crises do capitalismo. Lisboa: Bizâncio, 2011. KOSELLECK, Reinhart. Future pasts - on the semantic of historical time. New York: Columbia University Press, 2004 [1979].

LEFEBVRE, Henri.O direito à cidade. Lisboa: Letra Livre, 2012 [1968].

MARX, Karl.Trabalho assalariado e capital. 2. ed. Lisboa: Edições Avante,1981 [1891].

MEAD, Herbert George. The philosophy of the present. Chicago: The University of Chicago Press, 1932.

PIKETTY, Thomas. Capital in the Twenty First Century. Cambridge, MA: Belknap Press, 2014.

POLANYI, Karl. A grande transformação: as origens políticas e económicas do nosso tempo. Lisboa: Edições 70.Stiglitz, 2012 [1944].

SARTRE, Jean-Paul. A crítica da razão dialética. Rio de Janeiro: DP\&A editora, 2002 [1960]. 
STANDING, Guy. O precariado: a nova classe perigosa. Barcarena: Editorial Presença, 2014.

StIglitZ, Joseph E. Globalização: a grande desilusão. Lisboa: Terramar, 2004.

The price of inequality. Nova Iorque: W. W. Norton \& Company, 2012.

TEJERINA, Benjamín et al. From indignation to occupation: a new wave of global mobilization. Current Sociology, v. 61, n. 4, p. 377-392, 2013.

Veloso, Luísa; CARMo, Renato Miguel do. A constituição social da economia. Lisboa: Mundos Sociais, 2012.

Weber, Max. Fundamentos da Sociologia. Lisboa: Rés Editora, 1983 [1921].

ZIZEK, Slajov. Viver no fim dos tempos. Lisboa: Relógio d'Água, 2012.

\section{Renato Miguel do Carmo}

Sociólogo, atua no Instituto Universitário de Lisbora, Portugal. É diretor do Observatório das Desigualdades e membro do European Netword Inequality Watch. Contato: renatomiguelcarmo@gmail.com

\section{André Barata}

Possui doutorado em filosofia pela Universidade de Lisbora, Portugal. Atualmente é professor da Universidade da Beira Interior, Portugal. Contato: andrebaratanascimento@gmail.com 
